\title{
TEACHING AS
SCHOLARSHIP
}

Shane Neely-Smith, RN, MSN, Doctoral Student Lecturer, School of Nursing \& Allied Health Professions The College of The Bahamas

https://doi.org/10.15362/ijbs.v11i0.45

\section{Abstract}

As research and funding continue to replace teaching as the central mission in more colleges and universities, nursing faculty will be expected to engage in research endeavors as proof of scholarship involvement. However, the multiple roles of the nursing faculty coupled with the pressure to engage in research and funding endeavors have led to increased stress and burnout and increased attrition rate. The purpose of this paper is to delineate the expected roles of the nursing faculty related to the trilogy of teaching, research, and service and recommend that colleges/universities recognize not only research as scholarship, but also teaching and service. An integrative review of the literature using books and journals from nursing and other relevant disciplines related to the multiple roles of nursing faculty was conducted. Teaching is a vital role and should remain the central mission of colleges/universities to ensure effective pedagogy. Institutions of higher learning should adapt an umbrella of scholarship under which falls teaching, research, and service; thus, teaching should be considered scholarship.

Since the nursing profession has contracted to meet the health needs of society (Linderman, 2000), it is imperative that schools of nursing ensure that their faculty members engage in professional activities that will assist in this endeavor. Consequently, as with other college and university faculties, the nursing faculty is expected to engage in the trilogy of teaching, research, and service, for continuing contracts, promotions/increments, and tenure. However, due to an increased demand among many schools of nursing for faculty to engage in research funding (Meleis, 2001), an increased demand for innovative teaching to meet global needs (Ruby, 1999), the progressive nursing faculty shortage (Keating \& Sechrist, 2001; Hinshaw, 2001), and the push for nursing faculty to engage in clinical practice (Smolen, 1996), it is becoming more and more difficult for nursing faculty to adequately maintain these multiple roles. 
Some schools of nursing, particularly in developed countries such as the United States and Canada, expect nursing faculty to carry a full teaching load, while engaging in research, service, and practice each semester (Janocscrat \& Noll, 1989; Smolen, 1996). Moreover, scholarship-grant writing, research, and publication have greater value, especially in researchbased universities, than teaching and service (Melland \& Volden, 1996; Martsolf, Dieckman, Cartechine, Starr, Wolf, \& Anaya, 1999; Meleis, 2001). Although universities and colleges in developing countries such as those in the Caribbean are encouraging faculty involvement in research and service, presently teaching remains the main focus of these institutions. However, this focus might be broadened to become like that of developing countries as many universities/colleges in the Caribbean seek international accreditation. While research and funding are important prestigious endeavors, engagement in research should not be the only proof of scholarship; teaching should remain the central mission of universities/colleges. Consequently teaching and service should also be considered scholarship.

Generally, nursing faculty members spend most of their time teaching. However, the high demand for funding and research in colleges/universities puts more strain on an already overworked senior nursing faculty but especially a novice nursing faculty member. Among other roles, nursing faculty members are expected to engage in clinical practice to keep updated with new nursing skills and technological advancement in healthcare. Certainly, continuous practice can prove beneficial to the role of the nursing faculty, however, it increases the stress and strain of an already overworked faculty, leading to burnout (Voigneir, Hermann, \& Briouse, 1998) and increased attrition rate.

Fong (1990) conducted a study to examine the relationship between role overload, social support, and burnout among nursing faculty members. She concluded that bumout was directly related to faculty work overload. Hinshaw (2001) said there should be a balance and adequate pacing of the expected roles of the nurse faculty member to prevent excessive stress and burnout problems.

New nursing faculty coming into academia first need to get a "strong hold" on their teaching and adequately socialize themselves into academe, as opposed to straining to compete with experienced faculty to secure funding and engage in research. To make matters worse, new faculty are left to "swim or drown," because senior faculty have no time left from their heavy work load to mentor them (Hinshaw, 2001). Because of the magnitude of teaching, research, and service, nursing faculty should not be expected to engage in these endeavors all at the same time (Hinshaw, 1997). As contended by Glassick and colleagues (1997), engagement in any one of the trilogy of activities-teaching, research, and service-should be considered scholarship. In fact, faculty should be able to shift their focus on any of the three areas of scholarship as the need arises. For example, a faculty member might want to focus more on the scholarship of service and accept a lighter teaching load for a partioularenester. As a resut the gualty of the service rendered shoud be the yandetick by which scholathin is measured. 


\section{Teaching Considered}

Teaching ought to be considered extremely important in the learning process. In fact, almost everything one comes to know was taught either formally in the classroom or informally through social learning. Moreover, most persons go to school to acquire learning by being taught, and it is the quality of teaching that is valued most by society at large (Crawiord, 1998). According to Martsolf and colleagues (1999), however, most universities and colleges no longer view teaching as their central mission. Unfortunately, teaching has lost its place to research as a result of the struggle of institutions of higher education to achieve research and funding recognition. Yet teaching is the vehicle by which knowledge gained from research and service is transmitted to scholars and potential scholars for integration and application. Consequently, the role of teaching must be restored to its rightful place and its quality must be evaluated (Martsolf, et al., 1999).

Despite decreased recognition of the teaching role in most institutions of higher education, it still takes up a huge chunk of nursing faculty workload (Krahenbuhl, 1998). With the global knowledge explosion, increased health care demands, and changes in the socio-demographics of nursing students, there is increasingly more demand for nursing faculty to spend more time finding innovative ways to enhance knowledge transmission.

Technology and increased accessibility to computers have improved communication systems and opened the door to vast amounts of information to all people globally. Teachers can no longer go into the classroom unprepared without their students noticing. Furthermore, most students are up-to-date with societal changes, so, teachers are constantly forced to seek knowledge, in order to adequately meet the educational needs of their students.

Additionally, increased technology has bought on completely new dimen* sions in healthcare for society, affecting it socially, politically, and culturally. Persons are living longer, ironically leading to increased morbidity from chronic diseases and an increased need for healthcare; at the same time the cost of healthcare has escalated, resulting in decreased access to healthcare for many people; thus leading to a rise in preventable diseases and morbidity due to under-treatment. In addition, growing international migration has increased cultural diversity, cultural expectations, and healthcare demands. These new dimensions in healthcare mandate that nursing faculty keep abreast of current changes to adequately prepare young nurses to meet present and future healthcare challenges (McBride, 1999).

Unlike most other college/ university faculty, nursing faculty have not only classroom instruction as a part of their teaching load, but also clinical instruction and supervision. Moreover, a large part of basic nursing training is assigned to clinical teaching, so nursing faculty are constantly thinking of and developing innovative ways to enhance knowledge transmission to their students in the clinical area (Attridge, 1996). Additionally, nursing faculty have teaching obligations not only to the college/university, but also to the clinical institutions and the nursing council, which governs training/education and registration of nurses.

One time ago almost all students entering nursing programs were just out of high school. Today more and more nursing students are adults, with families 
and responsibilities, who come with a vast amount of life experience (Peters, 2000; Rice, 1992). Moreover, current nursing students make up a multiplicity of differing cultures (McGladney, cited in Vaughan, 1997). This sociodemographic change in nursing students has placed more demands for the nursing faculty to seek innovate ways to transmit knowledge. Nursing faculty must not only become culturally competent, but must know and be able to apply principles of adult learning, and be able to see themselves through the eyes of their students (Brookfield, 1995; Palmer, 1998) to enhance the teaching/learning process.

It is important to note that the role of teaching is more than just formal classroom and/or clinical teaching, which account for most of the nursing faculty workload. It also includes less noticeable teaching roles, such as preparing classes, preparing and grading tests, advising students, assisting students during office hours, mentoring students, consulting with students via e-mail, revising old courses and developing new courses, planning field trips and clinical visits. Professionally it involves collaborating with other educational institutions, reviewing textbook and curricular materials, engaging in curriculum development and revision, engaging in professional development such as attending educational workshops, seminars, conferences, and continuing education classes, and cross-moderating courses and tests prepared by other faculty members (Krahenbuhl, 1998; Janocscrat \& Noll, 1989).

The plethora of activities involved in the teaching role is not easy to master, especially for new faculty without educational preparation and teaching experience. According to Krisman-Scott and colleagues (1998), the trend for hiring nursing faculty has moved toward clinical expertise which poses a challenge for the nursing faculty coming into academia without teaching experience. Moreover, doctoral programs are not adequately preparing new nursing faculty for their teaching role (Anderson, 1998). The teaching role requires the nursing faculty to be involved in a substantial number of activities which require a great portion of their time and effort. How can the nursing faculty adequately assume the teaching role, while also struggling to maintain the role of research, service and practice? This unrealistic expectation of nursing faculty could lead to inadequate teaching preparation and knowledge transmission, dishonesty, feelings of isolation and frustration, and an increased attrition rate.

Like other college/university faculty, nursing faculty strive for teaching excellence and in their pursuit, automatically encounter research and service activities. Moreover, they are constantly involved in research within their teaching milieu, when they seek new and better ways to enhance students learning. For instance, Peters (2000) contends that the constructivist epistemology should be used to teach the nontraditional nursing students, who bring a wealth of experience with them into the classroom. Whenever nursing faculty inquire about diverse methods of pedagogy, apply them to the teaching/learning process, and then evaluate their effectiveness, they are engaging in research.

Participating in college/university governance is important for new faculty to become socialized to the academic environment, become familiar with 
the policies and procedures of academia, and have input into the day-to-day operation of these institutions. However, they should not be expected to be involved with more than two committees during their first year at the institution, unless they themselves feel the need to take on more responsibilities. In fact, they should not be forced into the competitiveness of engaging in research and securing funding until they have mastered the teaching role.

To assist the nursing faculty to achieve excellence in teaching, they should be evaluated formatively by their peers in clinical and classroom teaching. Through formative peer evaluation, the faculty can be given constructive feedback to enhance their pedagogical methods. However, as Ciesla (1997) contended, peers should be familiar with many educational paradigms, particularly positivist and interpretivist ones. This is important because a nursing faculty using pedagogy undergirded by the interpretivist paradigm, such as group discussions and small group projects, rnight be cited negatively by peers who might be unfamiliar with this paradigm. Consequently, the peer evaluation process might be viewed as an additional stress and strain for the nursing faculty, thus becoming an impediment to teaching excellence.

A closer look at the magnitude of the teaching role shows that teaching should be considered scholarship and excellence should be the only yardstick by which to measure it (Glassick, Huber, \& Maeroff, 1997). For continuing contracts, promotions/increments, and tenure, nursing faculty should be expected to prove that they have mastered the teaching role. Glassick and colleagues (1997) suggest a systematic approach to evaluate teaching as scholarship using quantitative and qualitative supportive data. They contend that all areas of scholarship (teaching, research, service) should be evaluated using the same criteria such as clear goals, adequate preparation, appropriate methods, significant results, effective presentation, and reflec-

- tive critique. Toward this end, the teaching portfolio Melland \& Volden, 1996) could be used to ensure the quality and effectiveness of the activities involved in teaching as scholarship. The teaching portfolio allows mursing faculty to gather qualitative and quantitative data from numerous perspectives, arrange them in an organized manner, and present them for evaluation by peers, administrators, and/or evaluating teams.

Accordingly, nursing faculty can compile materials reflective of teaching as scholarship such as lists of courses taught, course syllabi, teaching materials, tests, projects, instructional technology, teaching workshops and seminars attended, students' evaluations, peer evaluations, evidence of students' work (papers, tests, logs), student letters, photographs, to name just a few. These materials can be organized in a large ring folder and presented to the evaluating team to judge excellence in teaching.

\section{Conchmsion}

Most institutions of higher education, particularly in developed countries, have lost the primacy of teaching embedded within their mission, while competing for research and funding recognition. As a result, they are not adequately meeting the educational needs of their scholars and society at large. Additionally, this devaluation of teaching has indirectly escalated the nursing faculty shortage due to increased stress and strain placed on nursing faculty, particularly new nursing faculty without educational preparation and teaching experience. It would behoove institutions of higher edu- 
cation, especially those in the Caribbean Region, to adapt the umbrella of scholarship, to cover teaching, research, and service, as suggested by Glassick and colleagues (1997), and use excellence as the only yardstick by which to measure any one of these roles.

\section{Reterences}

Anderson, C. A. (1998). PhD graduates and the demands of faculty roles. Nursing Outlook, 46 (2), 53-54.

Attridge, C. B. (1996). Factors confounding the development of innovative roles and practices. Journal of Nursing Education, 35 (9), 406-412.

Bahrawy, A. A. (1992). Participation of nursing faculty in university governance. Journal of Nursing Education, 31 (3), 107-12.

Brookfield, S. D. (1995). Becoming a critically reflective teacher. San Francisco: Jossey-Bass.

Ciesla, I. S. (1997). Peer review: a method for developing faculty leaders. Nurse Educator, 22(6), 41-47.

Crawford, L. H. (1998). Evaluation of nursing faculty through observation. Journal of Nursing Education, 37(7), 289-294.

Fong, C. M. (1990). Role overload, social support, and burnout among nursing educators. Journal of Nursing Education, 29(3), 102-108.

Glassick, C. E., Haber, M. T., \& Maeroff, G. I. (1997). Scholarship assessed: evaluation of the professoriate. San Francisco: Jossey-Bass.

Hinshaw, A. S. (1997). Fighting success-facilitation of senior faculty. Journal of Professional Nursing, 13(6), 336

Janoscrat, A. J., \& Noll, L. F. (1989). Index of nursing faculty evaluation. Nurse Educator, $14(1), 24-29$.

Keating, S. B., \& Sechrist, K. R. (2001). The nursing shortage in California: the public policy role of The California Strategic Planning Committee for Nursing. Online Journal of Issues in Nursing. Retrieved February 5, 2001 from NURSINGWORLD on the World Wide Web: hitp:/ / wWw.nursingworld.org /top14/tpc14_2.htm

Krahenbuhl, G. S. (1998). Faculty work. Journal of Change, 30(6), 18-25. Retrieved on June 16,2001, from PROQUEST on-line database.

Krisman-Scott, M.A., Kershbaumer, R. M., \& Thompson, J. E. (1998). Journal of Nursing Education, 37(7), 318-320.

Linderman, C. A. (2000). The future of Nursing Education. Journal of Nursing Education, 33(1), 5-12.

Martsolf, D. S., Dieckman, B. C., Cartechine, K. A., Starr, P. I., Wolf, L. E., \& 
Anaya, E. R. (1999). Peer review of teaching: instituting a program in a college of nursing. Journal of Nursing Education, 38(7), 326-322.

McBride, A. B. (1999). Breakthroughs in nursing education: looking back, looking forward. Nursing Outlook, 47(3), 114-119.

Meleis, A. I. (2001). Scholarship and the RO1. Journal of Nursing Scholarship, 33(2), 104-105.

Melland, H. I., \& Volden, C. M. (1996). Teaching portfolios for faculty evaluation. Nurse Educator, 21(2), pp. 35-38. Retrieved June 2, 2001, from OVID online database.

Palmer, P. J. (1998). The courage to teach: exploring the inner landscape of the teacher's life. San Francisco: Jossey-Bass.

Peters, M. (2000). Does constructivist epistemology have a place in nursing education? Journal of Nursing Education, 39(4), 166-172.

Rice, C. P. (1992). Strategies and faculty roles for teaching RN students. Nurse Educator, 17(1), 33-37.

Smolen, D. M. (1996). Constraints that nursing program administrators encounter in promoting faculty change and development. Journal of Professional Nursing, 12(2), 91-98.

Vaughan, J. (1997). Is there really racism in nursing? Journal of Nursing Education, 36(3), 135-139.

- Voignier, R. R., Hermann, C. P., \& Brouse, S. H. (1998). Development of a faculty workload formula. Nurse Educator, 23(4), 35-39. 